\title{
Trends In Electric Vehicle (EV) Charging and Key Technology Developments
}

\author{
Mr. Navpreet Hans \\ Electrical \& Electronics Engineering Department \\ Bhagwan Parshuram Institute of Technology \\ New Delhi, India
}

\author{
Mrs. Shikha Gupta \\ Electrical \& Electronics Engineering Department \\ Bhagwan Parshuram of Technology \\ New Delhi, India
}

\begin{abstract}
As the Electric Vehicle (EV) sales are increasing day by day; a heavily electrified mobility is holding a promising future. With long-range Electric vehicles becoming a reality, the time consuming and inconvenient process to charge an EV is slowly becoming a major hurdle for consumers to accept the emobility revolution the auto industry is going through. This paper reviews the current state of the art technology used to charge an $\mathrm{EV}$, the types of chargers being used in the different regional auto markets and the key future developments being made in the charging field to make the charging experience of an EV owner less time consuming, effective and more convenient.
\end{abstract}

\section{INTRODUCTION}

One of the big impediments to broad adoption of electric vehicles (EVs) is just the frustration of these big bulky cables and always having to remember to plug in every day. As the numbers of EVs on the road are increasing day by day in the auto industry, primarily because environment protection and energy conservation are major concerns these days. Expanding e-mobility is an important building block on the road to a CO2-neutral balance. Government regulations to promote the use of EVs are a major factor in the increase of EV models by various companies. The number of EV models introduced by automotive companies is increasing rapidly with time [1]. The signal is clear that soon the gasolinepowered vehicles will be phased out and there will be a majority of EVs running on the road. The global sales of new electric vehicles for the first time passed a million units, in 2017. The annual passenger EV sales are expected to cross 10 million by 2025 [2]. As electric charging networks grow to provide electric vehicle drivers access to a wide and reliable infrastructure, energy systems will need to be prepared to supply the additional power required.

Modern-day EVs easily top the 200-miles mark of range being provided by their battery pack making the "poor range" factor less of a hurdle as developments are being made in the EV battery technology. With more than 350 new, featurepacked EV models to debut the car market by 2025. The factor of convenient and fast charging is slowly becoming the priority of consumers as well as the automakers. As emobility continues to grow charging solutions and bundles have been launched by several energy suppliers [3]. The purpose of this paper is to give an overview of how the EVs are being charged at present [4] and the key technological developments being done in the charging segment of the EV industry. The automotive industry is on the verge of profound change. It isn't just products and technology that must change; it is how people use these products and their entire experience of ownership [5].To give the consumers a better charging experience which is more convenient, efficient and less time consuming than what is being offered today. The paper begins with current methods available to charge an EV. Conductive AC, DC charging is explained in detail, followed by the key technological developments being done to improve our experience of charging the EV faster and more conveniently. Which covers - static inductive charging [6], dynamic inductive charging [7], battery swap [8] and smart charging technologies [9]. Subsequently, it discusses some examples from the industry who are working on these technologies aiming to launch in them in the near future and finally the conclusion. While the current power infrastructure can accommodate the rise in volume that would accompany greater EV penetration, a spike in peak demand could be overwhelming. To manage the charging of an increasing number of EVs, there is a need for applications that can coordinate the smart charging of EVs and reduce the impact of EV charging on the grid [10].

\section{METHODS TO CHARGE AN EV}

The main component in an electric vehicle is the battery pack inside it and it needs to be charged from time to time. There are various ways to charge it. The three common ways are -

1. Conductive charge

$$
\text { 1. } \mathrm{AC}
$$

2. $\mathrm{DC}$

2. Inductive charge

3. Battery swap

While the inductive charging has existed, it has still not been standardized yet. On the other hand battery swap technology is something which we hope to have in the future. Each method will be explained in detail as we proceed ahead in the paper.

\section{CONDUCTIVE CHARGING}

\section{A. Parts of an AC charger}

In its simplest form, AC charging uses an on-board charger to convert electricity from $\mathrm{AC}$ power (from the conventional AC grid) to DC power to charge the traction battery. Cars have a standardized vehicle inlet, and a charging cable is used to connect the vehicle connector to the AC charging station. In some cases, the charging cable is permanently connected to the charging station as well, similar to the petrol pump. There should be several essential components in an AC charging station for a safe and reliable charging process.

The essential components are shown in the power flow (fig 1) from the charger to the EV. The moment the charging station 
and the EV are connected. The charge controller in the station communicates the information regarding the connectivity, fault condition and current limits to the EV. Safety interlocks are used to ensure a safe charging process and to stop charging in the event of a fault condition an improper connection between the EV and the charger. As the AC power is provided to the $\mathrm{AC}$ the on-board charger has a rectifier which converts the AC power to DC power. Then the power control unit appropriately adjusts the voltage and the current of a DC/DC converter to control the charging power delivery to the battery. Since the power control unit is linked with the BMS (Battery management system) for controlling the battery charging. The BMS monitors the key battery operation parameters like the voltage, current and temperature. It then provides inputs to the power control unit to control the charging power delivered by the DC/DC converter. If the battery operating limits like the voltage or current are exceeded the BMS triggers the protection circuit inside the on-board charger, thereby isolating the battery if needed for its safe operation.

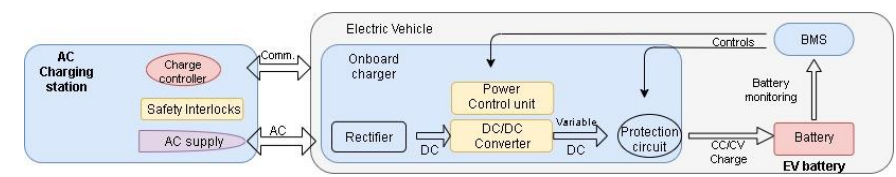

Figure 1 Basic AC charging configuration

\section{B. Types of AC Charger}

Due to the difference in AC voltage and frequency around the world, the EV industry has unfortunately not agreed on one specific AC connector, therefore depending upon the car brand and country, the shape, size and pin configuration vary in the connector. For example, in the USA, power is supplied using $120 \mathrm{~V}, 60 \mathrm{~Hz}$, dual AC or $240 \mathrm{~V}, 60 \mathrm{~Hz}$, dual-phase AC. On the other hand in Europe, $230 \mathrm{~V}, 50 \mathrm{~Hz}$, single-phase AC or $400 \mathrm{~Hz}$ three-phase AC is used. Due to these differences in voltages, the number of phases and frequency it leads to differences in chargers between the two regions.

Generally, an AC connector has two or more larger pins to transmit power and a few smaller pins for the sake of communication. There are four types of AC connectors (fig 2) used globally.

\section{AC Charger types : Overview}

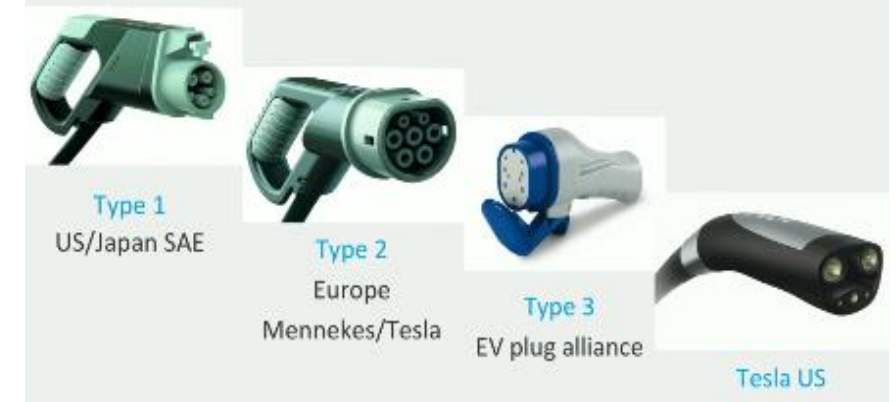

1. Type 1 connector

Figure 2 AC Charger types

- Used mostly in USA and Japan.
- Contains 2 pins for single-phase AC, one pin for protective earth, two signal pins used for communication.

- The maximum Voltage and current rating of this type are -Voltage $120 \mathrm{~V}$ or $240 \mathrm{~V}$; Current up to $80 \mathrm{~A}$.

2 Type 2 connector

- Mostly used all over Europe including European specification Tesla cars.

- The top row consists of two pins for communication, middle and lower row consists of five pins (three pins for three-phase AC and two pins for neutral and protective earth) used for AC power transfer.

- Maximum voltage and current ratings: 1 phase $230 \mathrm{~V}$, up to $80 \mathrm{~A} ; 3$ phase $400 \mathrm{~V}$, up to $63 \mathrm{~A}$.

3 Type 3 connector

- Used in Europe but is being increasingly phased out by the Type 2 connectors.

4 Tesla US connector

- In the case of Tesla, they use a proprietary connector.

- $\quad$ They use the Type 2 connector in Europe.

- Unlike other manufacturers, Tesla uses the same connector for both AC and DC charging.

- Maximum voltage and current ratings: 1 Max charging power of $17.2 \mathrm{~kW}$ when connected to 240V AC outlet.

AC charging or alternating current charging is the most common type of charger and its advantage is that the battery can be recharged anywhere, where there is a standard electrical outlet.

\section{Parts of DC Charger}

DC chargers are designed to quickly charge the electric vehicles. They operate at level 3 charging powers with an output ranging between $50 \mathrm{~kW}-350 \mathrm{~kW}$. DC chargers are implemented as an off-board charger rather than an on-board charger because with high power operation, the AC/DC converter, the DC/DC converter and the power control circuits become larger and more expensive, which makes it impractical to integrate it as an on board charger. Therefore to avoid taking up space within the vehicle they are set up as off-board chargers which can be shared by many users.

The power flow for DC charging (fig 3) from the DC charger to the EV battery is initiated by converting the AC power, provided by the AC grid to DC power using a rectifier inside the DC charging station. Then the voltage and the current of a DC/DC converter is appropriately adjusted by the power control unit. This is done so that the variable DC power delivered to charge the battery is controlled. The protection circuits and the safety interlocks used to de-energize the EV connector and to stop the charging process whenever there is a fault condition or an improper connection between the charger and the EV. The BMS plays the key role of controlling the voltage, the current and communicating with the charging station and to operate circuits in case of an unsafe situation. For example, CAN (Control area network) and PLC (Power line communication) are used for the communication between the EV and the charger. 


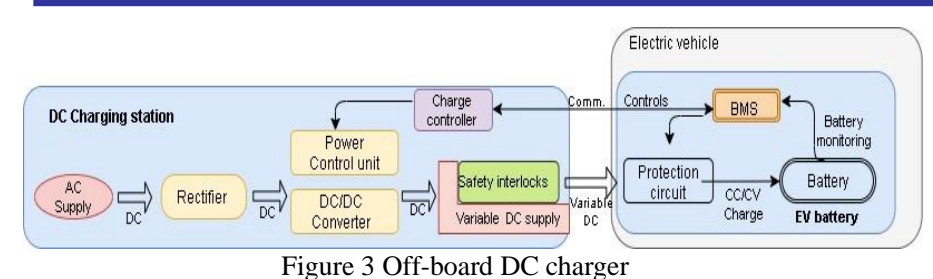

D. Types of DC Charger

DC charger connectors are derived from the AC charger connector types, and are of five types used globally-

1. CCS-combo 1

- Mainly used in the USA.

- The connector is derived from the AC type 1 connector.

- Two DC pins are added for fast charging, overall architecture remains the same as AC type 1 connector.

- Power line communication or PLC is used on the control pilot.

- CCS charger can deliver up to 350 Amps at a voltage of between 200 to $1000 \mathrm{~V}$ giving a maximum power output of $350 \mathrm{~kW}$.

2 CCS-combo 2

- Mainly used in Europe.

- Derived from the AC Type 2 connectors.

- Two DC pins are added at the bottom of the connector for high power DC charging, they retain the rest AC Type 2 connector pins.

- Power line communication or PLC is used on the control pilot.

- CCS charger can deliver up to 350 Amps at a voltage of between 200 to $1000 \mathrm{~V}$ giving a maximum power output of $350 \mathrm{~kW}$.

3 Chademo connector-

- Used globally for cars built by Japanese automakers.

- It is a type $4 \mathrm{EV}$ connector.

- It uses the CAN (control area network) protocol in the communication pins.

- The voltage, current and power levels of chademo are $50-500 \mathrm{~V}$, up to $400 \mathrm{~A}$, thus providing a peak power of $200 \mathrm{~kW}$.

- In the future, it is expected that EV charging up to $1000 \mathrm{~V}$ and $400 \mathrm{~kW}$ will be facilitated through this connector.

\section{Charger types : Overview}

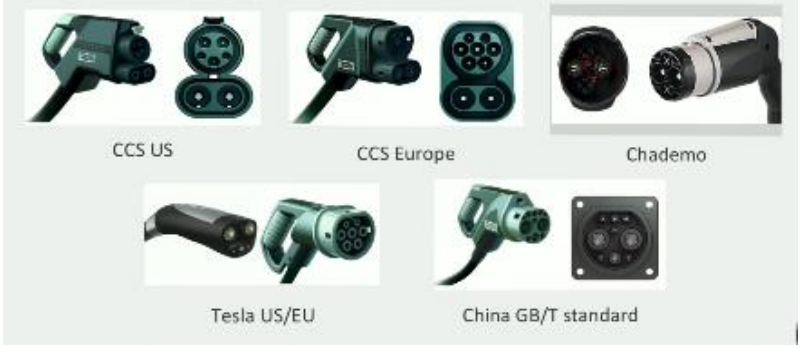

Figure 4 DC Charger types

4 Tesla Charger Connector-

- Tesla uses their own proprietary connector is the US, while the European variant uses the Type 2 connector with DC charging built-in.

- They use the same connector for both $\mathrm{AC}$ and DC charging.

- They offer DC charging up to $120 \mathrm{~kW}$; this is expected to increase in the future.

5 DC Charger - China GB/T standard

- China's own DC connector.

- It uses the CAN bus for communication.

- Has five pins, two for low voltage auxiliary power and one for ground.

- It has four signal pins, 2 for proximity pilot and two for CAN communication.

- Maximum current 250A

- Nominal Voltage $750 \mathrm{~V}$ or $1000 \mathrm{~V}$.

\section{FUTURE DEVELOPMENTS IN EV CHARGING}

The charging technologies are being constantly improved to provide a much better, hassle-free and less time-consuming EV charging experience. With the electric car market being established in many countries, key developments are being to ease the main drawback a customer thinks about- charging time/experience. The main technological developments we might experience in the future are-

\section{1) Inductive charging - static charging}

The concept behind inductive charging is the use of two electromagnetically linked coils. The primary coil is placed on the road surface, in a pad-like construction linked to the electricity network. The secondary coil is placed on the vehicle, ideally on the bottom of the car, at a safe distance from the passengers. Within the charging station, the $\mathrm{AC}$ is rectified and converted to a high-frequency $\mathrm{AC}$ power. Within the charger station; this high-frequency power is transferred to the EV side by induction. The main aim behind incorporating the wireless charging method in EVs is to make less mess than conductive charging since it has no cable, hence is more convenient. For self-driving cars, wireless communication can take care of everything, no plug behavior needed.

Witricity Corporation, an American company that works on wireless charging technology which is just as efficient as conductive chargers aim to introduce wirelessly charged EVs and PHEVs (Plugin Hybrid Electric Vehicles) over the course of next three to four years. One of the big impediments to 
broad adoption of electric vehicles is just the frustration of the bulky cables and having to remember to plugin. Witricity Corporation aims to take this clumsy charging process out of the day to day lives of the people and provide technology with no user intervention at all. Just park your EV and it charges on its own. Wireless charging is a key enabler to the broad adoption of electric vehicles. They also focused on standardization of their technology making it interoperable from one automaker to another by working closely with almost all of the global automakers, thereby making its technology more practical to use in the future.

\section{2) Inductive charging - Dynamic charging}

There is another way to charge a car wirelessly- the dynamic charging, which is similar to static inductive charging. The energy transfer from the charger to the car is through magnetic coupling. Coils connected to electric cables that are used to provide power are buried in the road. The coils produce an electromagnetic field which is picked up by the vehicles driving over them which is converted into electricity to charge the cars. The advantages of inductive dynamic charging are that it provides a low stand in charging time for customers. The battery size can be smaller as the battery pack can be charged regularly on the road. The main barriers of this technology are related to power transfer efficiency, as foreign objects on the road, abrasion of the surface of the road, and the coil structure changes inside the road-building materials may impact the features of the coil and reduce the power transfer efficiency.

Qualcomm Technologies, Inc. (QTI), one of the few companies working on dynamic wireless charging has developed a technology known as "Qualcomm Halo" intending to provide a simple and efficient way to charge electric vehicles. QTI's Dynamic electric vehicle charging (DEVC) system is capable of charging an EV dynamically at, and above $100 \mathrm{~km} / \mathrm{h}$ with $20 \mathrm{~kW}$.

DEVC technology was a result of a research undertaken at Qualcomm's Auckland facility where the concept had been proven at low speed, the original objective of the project was to demonstrate how WEVC applies to dynamic charging. So far the dynamic inductive charging technology is still under the experimental stage due to many challenges to standardize it. These are -

- Different ground clearances, car size and power level that could lead to sub-optimal operations.

- Choosing a universal high- performance coil-type for dynamic charging is a challenge.

- Real-time coil misalignment for different types of cars is hard to estimate.

Hence this technology is still far away from being commercialized.

\section{3) Battery swap Technology}

As the name suggests, this technology works on the basis of switching out the depleted battery and replacing the same battery with a fully charged battery. It involves driving into the battery switching bay, which through an automated process will position the vehicle and switch out the current battery and replace it with a fully charged battery. The depleted batteries are then charged in the station for later deployment. The advantage of a battery swap technology is that it eliminates range anxiety and is just like refilling a tank, quick and easy. On paper, this technology has a lot of advantages but to get market acceptance would be a real challenge for such a technology, mainly because of the following reasons -

- A standardized battery would be required across all auto manufacturers to practically use this technology.

- It would be difficult for the consumers to accept a battery which they don't own and having to change the vehicle battery.

- There should be a foolproof way to estimate the state of health of a battery and analyze the usage pattern.

- The constant connection between the battery and the vehicle would need to be made and broken each time a battery is swapped. The electrical connection between the battery and the vehicle carries a very high current which causes a major safety concern for the customer, as every time a swap is done it will cause wear and degradation at the key link between the two components and at worst has the potential to cause a massive discharge.

Nio, a Chinese carmaker of electric vehicles launched its battery-swapping scheme with its first electric vehicles back in 2018. Having completed more than 500,000 battery swaps. Nio's battery swapping system can perform a fully automated battery swap in 3 minutes. As of June 2020, NIO had built 135 power stations spread across 59 cities in China and continues to expand. It offers a free battery swap service to its EV users thereby creating a great business model to make it a successful service. China is the only region in the world where the battery swap technology has proved to be successful, particularly because of the fact that China is the largest market for electric vehicles in the world.

\section{4) Smart Charging}

With our lives increasingly being heavily dependent on electricity including electric vehicles, to use it effectively and efficiently will be very crucial in the future. Smart charging is a series of intelligent functionalities to control the EV charging power in order to create a flexible, sustainable, low cost, and efficient charging environment. Innovative technologies can help us manage how we use energy more efficiently and balance the demand on the grid. Analyzing the daily peaks and troughs in the energy demand, future electric charging solutions are being developed to optimize the use and provide stored energy back to the grid. Vehicle to grid charging and smart charging (also known as V2G) are such two technologies that can play a vital role in this act of balancing.

Shell, a global group of energy and petrochemicals, has launched a smart EV charging service including tariff and charger. Shell- owned NewMotion will be offering a charger capable of providing $7 \mathrm{~kW}$ of power, charging a typical $\mathrm{EV}$ in 
five hours. It will be powered by $100 \%$ renewable energy since Shell switched to $100 \%$ renewables last year as it rebranded. The company also provides a shell recharge app through which customers can have access to 155,000 charge points in over 5 countries. NewMotions charge card and app offer access to the largest charging network of Europe, which is expanding every day.

\section{CONCLUSION}

The way we transmit power to charge our electric vehicles might change drastically in the upcoming years, which will indirectly help in the broad adoption of EVs. Starting from the different charger types used in the various regions of the world to working on wireless and battery swap technology, these initiatives in future development will immediately increase the convenience of owning an EV. The main advantage of owning an electric-powered vehicle is the feature of electricity to be used as a commodity since the whole world has moved on to electrification one can use its $\mathrm{EV}$ as a powerhouse and charge other devices during an emergency by using the V2G technology. Since an EV can be charged anywhere, the option to charge an EV while moving is also something tech companies have been working on to make the ownership experience of an EV more or as convenient as gasoline-powered cars. With many roadblocks to practical and global adoption of these future charging technologies, the fact that developments are being constantly made by companies and in some cases, the new technology is also being commercially available in some heavily EV dominated auto markets like the battery swap technology in China, shows us the scope of a future where the traditional charging methods being used in the current times will soon fade out as our auto industry gets increasingly electrified on a global scale. In conclusion, there is still a long way to go, to charge the battery of an EV in a more convenient, efficient and stable manner.

\section{REFERENCES}

[1] Anon., "Electric Vehicle Market by Vehicle (Passenger Cars \& Commercial Vehicles), Vehicle Class (Mid-priced \& Luxury), Propulsion (BEV, PHEV \& FCEV), EV Sales (OEMs/Models) Charging Station (Normal \& Super) \& Region - Global Forecast to 2030," Markets and Markets,. Rep: AT 4907, June 2019. Available: https://www.marketsandmarkets.com/Market-Reports/electric-vehiclemarket-209371461.html

[2] M. Agrawal, M.S. Rajapatel. (2020, Jan). "Global Perspective on Electric Vehicle 2020. International Journal of Engineering Research and Technology [Online]. Volume 9, Issue 01. Available: https://www.ijert.org/research/global-perspective-on-electric-vehicle2020-IJERTV9IS010005.pdf

[3] Alice.Grundy. (2020, Feb. 20). Shell Energy launches EV charging bundle offering 2,000 miles free charging [Online]. Available: https://www.current-news.co.uk/news/shell-energy-launches-evcharging-bundle-offering-2-000-miles-free-charging

[4] Amsterdam Roundtable Foundation and McKinsey \& Company The Netherlands, "Electric vehicles in Europe: gearing up for a new phase?, " McKinsey \& Company, Netherlands, April 1, 2014. Available: https://www.mckinsey.com/featured-insights/europe/electric-vehiclesin-europe-gearing-up-for-a-new-phase

[5] Nio. (2020, Jun. 29). A Brief History of Battery Swapping [Online] Available: https://www.nio.com/blog/brief-history-battery-swapping

[6] Witricity.(2020). Drive Solutions [Online]. Available: https://witricity.com/products/automotive/

[7] Qualcomm. (2017,May.18.). From wireless to dynamic electric vehicle charging: The evolution of Qualcomm Halo [Online]. Available: https://www.qualcomm.com/news/onq/2017/05/18/wireless-dynamicev-charging-evolution-qualcomm-halo

[8] Fred Lambert.(2020,Jun,2.).Nio Might Have Figured Out Battery Swap For Electric Cars As It Completes 500,000 Swaps [Online]. Available:https://electrek.co/2020/06/02/nio-battery-swap-electric-carscompletes-500000-swaps/

[9] Shell.(2020) Electric Vehicle Charging [Online]. Available: https://www.shell.com/energy-and-innovation/new-energies/electricvehicle-charging.html

[10] Prof.Dr. Pavol Bauer, Dr Gautham Ram Chandra Mouli (Delft University of Technology). Electric Cars: Technology [Online] Available:https://courses.edx.org/courses/coursev1:DelftX+eCARS2x+ 3T2019/course/ 